\title{
A LÓGICA NO CONTEXTO DA PESQUISA CIENTÍFICA: UMA ABORDAGEM METODOLÓGICA
}

\author{
Alva Rosa Lana Vieira ${ }^{1}$ \\ Rosa Mendonça de Brito ${ }^{2}$ \\ Suely Oliveira Moraes Marquez ${ }^{3}$ \\ Bárbara Castro Lapa ${ }^{4}$ \\ Jucimara Canto Gomes 5
}

RESUMO: A proposta precípua deste artigo é mostrar a importância da Lógica no contexto da pesquisa científica por meio de cinco sessões, a saber: Contextualização da Lógica; A importância do raciocínio lógico para o ser humano; Um olhar para a gênese da lógica segundo Heráclito e Parmênides; A Lógica Formal; A Lógica Dialética. A composição das sessões deste estudo caminham para o tratamento da Lógica como o estudo do raciocínio, ou seja, dos sistemas que definem como pensar de forma mais crítica no que diz respeito a opiniões, inferências e argumentos, conduzindo à produção de sentido ao pensamento. Para tanto, foi realizada uma sistematização que evidenciou a contextualização da Lógica, bem como a relevância da mesma para a vida do ser humano, além dos encaminhamentos da Lógica Dialética nesse processo.

Palavras-chave: Lógica. Pesquisa Científica. Abordagem metodológica.

\footnotetext{
${ }^{1}$ Mestrado em Gestão e Avaliação da Educação Pública pela Universidade Federal de Juiz de Fora e doutoranda em Educação pela Universidade Federal do Amazonas. É pesquisadora, vinculada ao grupo de pesquisa Grupo de Estudos e Pesquisas em Educação Escolar Indígena e Etnografia, da Universidade do Estado do Amazonas. Graduada em Licenciatura de Matemática, especialização em Ensino de Matemática pela Universidade Federal do Amazonas. Atualmente está lotada na Coordenadoria Regional de Educação de São Gabriel da Cachoeira da Secretaria de Estado da Educação e Qualidade do Ensino do Amazonas

${ }^{2}$ Pós-Doutora na área de Filosofia da Educação junto ao Instituto de Filosofia da Universidade Federal do Rio de Janeiro. Doutora em Filosofia pela Universidade Gama Filho. Mestra em Filosofia pela Pontifícia Universidade Católica do Rio de Janeiro. Atualmente é professora pesquisadora Titular da Universidade Federal do Amazonas. Associação Francofone de Pesquisa em Educação.

${ }^{3}$ Mestrado em Sociedade e Cultura na Amazônia pela Universidade Federal do Amazonas. e Doutorado em Educação pela Universidade Federal do Amazonas/UFAM. Professora Adjunto nível IV da Universidade Federal do Amazonas. Tem experiência na área de Ciência da Informação, com ênfase em Biblioteconomia. ORCID - https://orcid.org/oooooooi-878I-5349.

${ }^{4}$ Mestra em Ensino Tecnológico pelo Instituto Federal de Educação, Ciência e Tecnologia do Amazonas (IFAM). Doutoranda no Programa de Pós-graduação em Educação (PPGE) pela Universidade Federal do Amazonas (UFAM). Licenciada em Ciências Biológicas pelo Instituto Federal de Educação, Ciência e Tecnologia do Amazonas (IFAM) Professora de Biologia/Ciências na rede pública de ensino do Amazonas (SEDUC-AM), no Centro de Educação de Jovens e Adultos (CEJA) Professora Jacira Caboclo.

5 Doutoranda em Educação na Universidade Federal do Amazonas (UFAM). Mestrado em Educação (UFAM). Especialização em Tecnologia Educacional (UFAM). Especialização em Design Instrucional (IDI). Especialização em Formação e Gestão em Educação a Distância (UNIP). Licenciatura em Pedagogia pela (UFAM). Atua como Pedagoga na Coordenação de Educação a Distância do Centro de Formação Profissional Pe. José Anchieta CEPANSEDUC/Manaus. Participa do Grupo de pesquisa: Comunicação, Tecnologia e Cultura na Educação Presencial e a Distância. Líderes: Zeina Rebouças Corrêa Thomé e Luiz Carlos Cerquinho de Brito. Experiência em Docência Superior como Professora Substituta no Instituto de Ciências Sociais, Educação e Zootecnia-ICSEZ/UFAM e PARFOR. Currículo Lattes: http://lattes.cnpq.br/o751124082793845. ORCID: https://orcid.org/oooo-oooi-8166-3436
} 
ABSTRACT: The main purpose of this article is to show the importance of Logic in the context of scientific research through five sessions, namely: Contextualization of Logic; The importance of logical reasoning for the human being; A view about the genesis of logic according to Heraclitus and Parmenides; Formal Logic; Dialectical Logic. The study sessions composition move towards the treatment of Logic as the study of reasoning, that is known as systems that define how to think more critically with regard to opinions, inferences and arguments leading to the production of meaning in thought. For that, a systematization was carried out that evidenced the contextualization of the Logic, as well as its relevance for the human being's life, in addition to the Dialectical Logic's referrals in this process.

Keywords: Logic. Scientific research. Methodological Approach.

\section{INTRODUÇÃO}

O conhecimento que as antigas civilizações detinham e conseguiram deixar como contribuição para a existência do ser humano é fascinante. E nisto a contribuição do mundo grego é uma marca indelével para a humanidade no que se refere à Filosofia e inserida nela a Lógica. São diversos os estudos e os atores que fizeram parte desse contexto, entre os quais Heráclito, Parmênides, Sócrates, Platão e Aristóteles são citados.

$\mathrm{Na}$ idade média, importantes intelectuais contribuíram para o aperfeiçoamento da lógica aristotélica. A lógica foi considerada "ciência de todas as ciências”. A palavra 'lógica' está presente na nossa vida desde muito cedo, mas a sua compreensão, assim como ocorre com muitas outras palavras e suas respectivas definições, sofre variações à medida que vamos crescendo e observando o mundo com outros olhos.

No início dos nossos entendimentos enquanto seres humanos a lógica representa aquilo que é certo (ou a certeza de algo). E dessa forma surge sempre o questionamento: Mas afinal, o que significa lógica? Praticamente todos já foram questionados a respeito do tema em algum momento da vida, e para muitos em mais de uma ocasião. Seja nas aulas de Filosofia, Física e Matemática, o estudo da Lógica, ou uma introdução a respeito da mesma, é obrigatória.

Não por acaso, a resposta a essa questão nunca é dada de maneira clara e direta. É preciso refletir sobre o assunto para só depois construir um conhecimento proveniente dele, e não apenas aceitá-lo passivamente. Desse modo, percebe-se a contribuição da Lógica enquanto modo/instrumento de organizar o pensar inserido em um contexto. 
A aprendizagem da lógica faz com que o pensamento proceda corretamente a fim de chegar a conhecimentos verdadeiros. Assim, pode-se afirmar que a lógica trata do estudo do raciocínio, ou seja, dos sistemas que definem como pensar de forma mais crítica no que diz respeito a opiniões, inferências e argumentos, conduzindo à produção de sentido ao pensamento.

Nessa perspectiva de apresentar uma abordagem metodológica à Lógica no contexto da pesquisa científica, serão apresentadas cinco sessões neste artigo, a saber: Contextualização da Lógica; A importância do raciocínio lógico para o ser humano; Um olhar para a gênese da lógica segundo Heráclito e Parmênides; A Lógica Formal; A Lógica Dialética; além de considerações finais e respectivas referências.

\section{CONTEXTUALIZAÇÃO DA LÓGICA}

Pensar logicamente não é pensar certo ou errado. A lógica não se ocupa em mostrar como as pessoas raciocinam, mas sim se as coisas que sabemos - ou nas quais acreditamos - são de fato uma boa razão para validar uma conclusão. Somado a isto, a lógica verifica se esta conclusão é justificável em consequência das informações que tínhamos quando iniciamos o processo do pensamento.

Os sofistas e Platão já haviam se dedicado a questões lógicas, mas nenhum deles alcançou tal amplitude, rigor e sistematização quanto Aristóteles. Sua obra Analíticos, somada a outras, foi posteriormente denominada Órganon, que significa "instrumento", ou seja, instrumento para pensar com correção. A palavra lógica começou a ser usada mais tarde, provavelmente com os estóicos.

Embora a lógica tenha uma origem filosófica, pois Aristóteles é considerado o pai da lógica, ela transcende os muros da Filosofia.

Normalmente associa-se a Lógica apenas à matemática, o que não é verdade, pois a Lógica se aplica a todas as situações do cotidiano e a todas as ciências. Ela está presente em todas as áreas do conhecimento, em qualquer âmbito onde tiver argumentação. $\mathrm{O}$ pessoal do direito, os cientistas, os matemáticos, os biólogos, os historiadores, todos estão interessados e utilizam-se da lógica, porque onde tiver argumento, onde tiver pretensão de verdade à lógica estará lá. 
Se afirmarmos algo querendo sustentar a verdade daquele algo não basta afirmar, tem que justificar. $O$ conhecimento passa por uma tentativa de justificação das suas afirmativas. Então a origem dela é filosófica, mas hoje em dia ela transcende a filosofia.

A lógica está presente o tempo inteiro nas nossas vidas, no nosso dia a dia, nós manipulamos as informações. Se dermos um conjunto de informações para uma pessoa, ela será capaz de sozinha inferir outras informações que não foram dadas inicialmente.

Para maior profundidade deste trabalho, necessita-se saber qual a definição de Lógica. Para tanto, alguns autores, que estudam a Lógica, foram consultados bibliograficamente.

Forbellone e Eberspãcher (2005, p. I-2) dizem que:

'[...] a Lógica relaciona-se com a correção do pensamento' [...] e também é 'a arte de bem pensar', [...] é 'a ciência das formas do pensamento', visto que, 'a forma mais complexa do pensamento é o raciocínio'. 'A Lógica estuda a correção do raciocínio'. [...]. 'A Lógica estuda e ensina a colocar ordem no pensamento'.

Para Copi (1978, p. 19) "Lógica é o estudo dos métodos e princípios usados para distinguir o raciocínio correto do incorreto".

Já Maritain (1980, p. 22) diz que "Lógica é a arte que dirige o próprio ato da razão, isto é, que nos permite chegar em ordem, facilmente e sem erro, ao próprio ato da razão”.

Pode-se observar que em todas as citações, os autores definiram a Lógica de maneira similar. Veja-se: "A Lógica é a correção do pensamento"; "A Lógica é a ciência das formas de pensar, visto que a forma mais complexa de pensar é o raciocínio"; "A Lógica estuda a correção do raciocínio” (FORBELLONE e EBERSPÃCHE, 2005, p. I); “A Lógica é a ciência do raciocínio e da demonstração" (LIARD, I965); "A Lógica é o estudo dos métodos e princípios usados para distinguir o raciocínio correto do incorreto" (COPI, 1978, p. 19); "A Lógica é a ciência do raciocínio e da demonstração" (AVILLANO, 2006, p. $35)$.

Assim podemos dizer que a Lógica é a ciência das formas do pensamento, ou seja, pode-se concluir que a Lógica é a forma de raciocinar até mesmo para realizar pequenas atividades cotidianas, visto que, ensina a colocar ordem no pensamento.

Percebe-se em cada etapa desse estudo, que há uma necessidade de aprofundar-se no mundo da pesquisa, entender e decifrar como se pode através do raciocínio lógico, tomar decisões inteligentes. 
Esse estudo define a Lógica e sua real necessidade no cotidiano das pessoas, porém a Lógica é muito abrangente e digna de muitas pesquisas, pois como já foi dito, se aplica em todas as ciências. $\mathrm{O}$ raciocínio pode ser correto ou incorreto. $\mathrm{O}$ seu estudo ultrapassa os limites da percepção, visto que, o ser humano é extremamente complexo.

A lógica tem como objetivo, à procura e a demonstração da verdade, através das dificuldades e da refutação dos erros. A lógica é um instrumento poderoso para ajudar o ser humano a justificar suas operações recorrendo aos princípios que fundam sua legitimidade.

\section{A IMPORTÂNCIA DO RACIOCÍNIO LÓGICO PARA O SER HUMANO}

Rapidamente a tecnologia avança e em pouco tempo os aparelhos de última geração estarão ultrapassados. A ideia é que todos tenham pensamentos lógicos para acompanhar as mudanças em tão pouco espaço de tempo.

É indispensável que o ser humano tenha um raciocínio lógico para organizar os pensamentos e assim obter bons (e quem sabe, ótimos) resultados em suas atividades cotidianas.

Para formar uma frase coerente e com coesão, é necessário realizar pensamentos lógicos no cérebro para ordenar as letras, sílabas, palavras, para que, a quem esteja sendo dirigida, entenda perfeitamente. Por esse motivo, pode-se dizer que existe Lógica no dia a dia. Quando falamos ou escrevemos, estamos usando-a. Percebe-se a importância da Lógica na prática, pois há o desejo de pensar, falar, escrever e agir de maneira correta. Para que isso aconteça, as pessoas ordenam seus pensamentos, de forma que estão utilizando a lógica e o raciocínio lógico para as atividades tão básicas no cotidiano.

\section{UM OLHAR PARA A GÊNESE DA LÓGICA SEGUNDO HERÁCLITO E PARMÊNIDES}

Ao considerar a Lógica como a "ciência do raciocínio e da demonstração" (AVILLANO, 2006, p. 35), cabe um olhar específico ao processo de construção dos caminhos que conduziram ao entendimento do que se conhece e concebe como Lógica na atualidade, bem como das diversas abordagens de sua utilização. Desse modo, analisando a Figura abaixo, tem-se a Lógica debruçada, sobretudo na linguagem e, de modo particular, nos processos discursivos, de pensamento e da verdade. 
Figura I - Ponto de partida do pensamento lógico

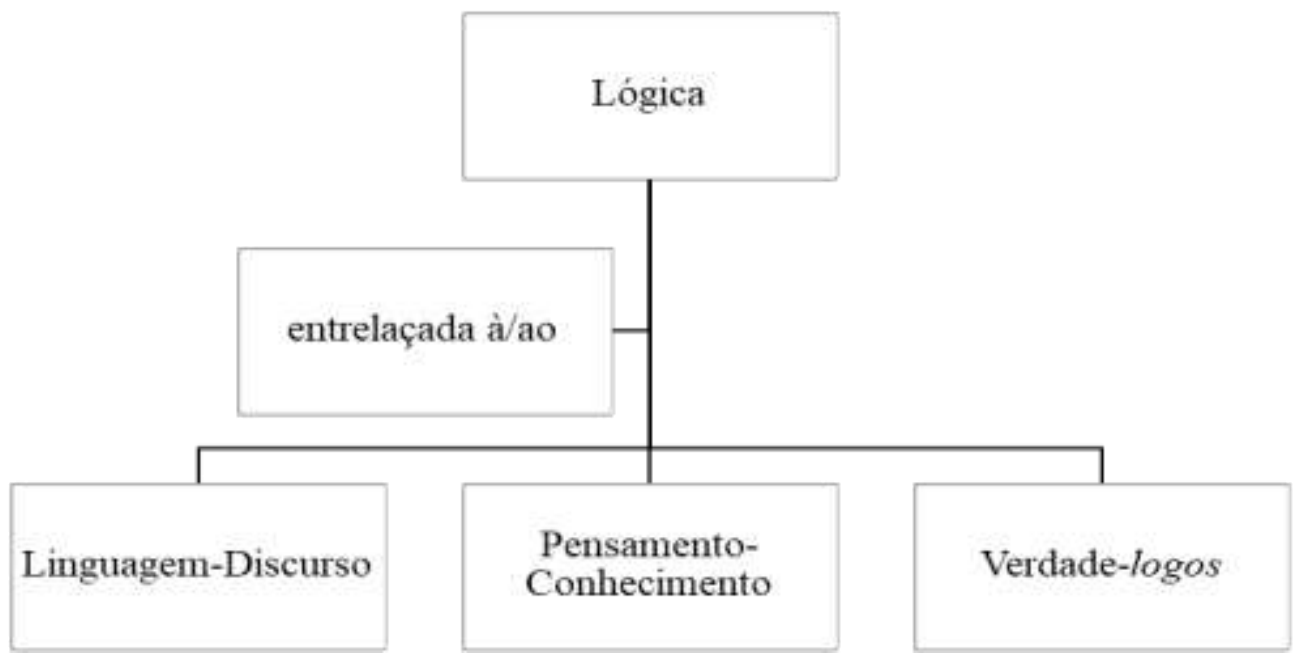

Fonte: As autoras (202I).

Conforme exposto, compreende-se também que partindo do discurso se tem a expressão de um pensamento organizado e concebido de acordo com o conhecimento individual e/ou coletivo dotado de significado e, mormente, de sentido. Assim, cabendo trazer à tona os conceitos de verdade e logos, entendidos na gênese da história da Filosofia grega em Heráclito e Parmênides:

Assim, Heráclito afirmava que a verdade e o logos são a mudança das coisas nos seus contrários, enquanto Parmênides afirmava que são a identidade do Ser imutável, oposto à aparência sensível da luta dos contrários. Parmênides introduz a ideia de que o que é contrário a si mesmo, ou se torna contrário do que era, não pode ser (existir), não pode ser pensado nem dito porque é contraditório, e a contradição é o impensável e o indizível, uma vez que uma coisa que se torne oposta de si mesma destrói-se a si mesma, torna-se nada. Para Heráclito, a contradição é a lei racional da realidade; para Parmênides, a identidade é essa lei racional (CHAUÍ, 2000, p. 228).

Tendo se constituído esses modos de pensar a construção da verdade e do logos, propostos por Heráclito e Parmênides, um processo de compreensão dos caminhos do raciocínio. Fato que conduziu, mais tarde, tanto Platão quanto Aristóteles a problematizarem tais questões.

Dessa forma, na tentativa de elucidar essa problemática, Platão considerou que Heráclito possuía razão quanto ao mundo material, ou seja, ao mundo dos seres corporais, visto que a matéria está sujeita a mudanças contínuas e oposições internas (CHAUÍ, 
200o). Estando Heráclito correto no que tange ao mundo natural ou das percepções (mundo sensível, das aparências), o qual figura em um estado de devir permanente.

Em concordância com Parmênides, Platão reconheceu também seu pensamento como correto no que se refere ao entendimento do mundo verdadeiro como sendo o inteligível (mundo das essências imutáveis), sem a possibilidade de contradições nem oposições, sem transformações, no qual não há meio de um ser passar para uma condição que lhe seja contraditória, como reforça Chauí (2000).

Nesse contexto de superação dos contraditórios e chegada ao que é sempre idêntico a si mesmo, à identidade de uma essência, Platão revela a discussão dialética como um modo de conhecer, isto é, uma possibilidade de descortinar o mundo sensível, tal como heraclitiano, dotado da luta entre contrários, bem como das mudanças permanentes, e o mundo inteligível, conforme parmenidiano, no qual a identidade é considerada de modo perene.

E, enquanto Platão segue um percurso de compreensão do raciocínio como um modo de conhecer por meio da dialética, Aristóteles propõe a não separação da realidade e da aparência em dois mundos distintos, visto que compreende a coexistência de ambas, fato que o conduziu ao entendimento de que:

Parmênides tem razão: o pensamento e a linguagem exigem a identidade. Heráclito tem razão: as coisas mudam. Ambos se enganaram ao supor que a identidade e mudança são contraditórias. Tal engano levou Platão à desnecessária divisão dos mundos (CHAUÍ, 200o, p. 230).

Nesses termos, ainda segundo a autora acima referenciada, Aristóteles propôs pensar um conjunto de procedimentos de demonstração e prova, o qual nomeou de Analítica, e mais tarde foi classificado como Lógica. Tal contexto, na perspectiva aristotélica, conduziu a Dialética platônica para fins retóricos, políticos, oratórios, de teatro e de persuasão, dando espaço e especial evidência ao desenvolvimento da Lógica Formal.

\section{A LÓGICA FORMAL}

Conforme Hegel, ainda não existe a história da Lógica Formal, apenas esboços, ela seria a história de todo conhecimento na grandeza do seu desenvolvimento. Mas muitos professores de Matemática e Filosofia afirmam a importância da Lógica Formal para se pensar. Essa situação se configura ao tratarmos algumas demonstrações contábeis, 
teoremas e proposições filosóficas que são acusados de não terem legitimidade lógica. Assim como o Latim, a Lógica formal deixou de ser ministrada nas escolas.

Etimologicamente a Lógica vem do grego logos que significa "palavra”, “expressão”, “pensamento”, “conceito”, “razão”. Para Aristóteles "Lógica é a ciência da demonstração”. Em que podemos exemplificar o Teorema de Pitágoras, que é demonstrado observando as regras da Lógica (PATRUS, 2002 p. 135).

Contudo, a Lógica se divide em Lógica Formal e Lógica Material ou Dialética. A Lógica Formal estuda as formas do pensamento no que estas tenham de geral e de comum. A Lógica Material ou Dialética é o conjunto de regras que devemos seguir para ordenar bem a matéria dos atos de inteligência, a fim de obter um conhecimento científico que nos permita chegar à verdade.

A Lógica Formal trata da relação entre as premissas e a conclusão, deixando de importar-se com a verdade das premissas. A ela, interessa apresentar as regras do pensamento correto. É um instrumento que ajuda o caminhar do filósofo ou do pesquisador. $\mathrm{O}$ certo ou errado da lógica de um argumento depende da relação entre a premissa e a conclusão. A Lógica Formal ajuda a determinar se as premissas dadas sustentam a conclusão.

Com isso, a Lógica Formal é uma ferramenta utilizada para desenvolver cadeias de pensamento, que permite reconhecer contradições e eliminar probabilidade de erros. Visa desenvolver a capacidade de discernimento e identificar raciocínios válidos e não válidos. Sendo importante compreender que nem todo raciocínio é lógico. Seguem alguns elementos, bem como exemplos, do raciocínio lógico:

a) Termo: Componente básico da proposição, qualquer substantivo, adjetivo ou nome próprio de um enunciado.

b) Proposição: É um enunciado, uma proposição bem formada, declarativa. Funcionalidade do julgamento verdadeiro ou falso. Primeira premissa do silogismo.

c) Silogismo: É um raciocínio que, a partir de duas proposições que são aceitas como verdadeiras, leva de maneira necessária a uma conclusão. Segundo o Aristóteles, o silogismo é o coração da Lógica e a teoria das demonstrações ou das provas, da qual depende o pensamento científico e filosófico. 


\section{I) Exemplo I:}

Todo homem é mortal - Premissa maior.

João é homem - Premissa menor

Logo, João é mortal - Conclusão

Apresentam-se dois tipos de argumentos chamados:

Silogismo Dedutivo que é uma inferência conduzida dos princípios para uma consequência necessária. Ideia que parte da proposição universal para particular.

\section{2) Exemplo II:}

Todo jovem de 16 anos pode votar.

Maria tem I6 anos.

Logo, Maria pode votar

Silogismo Indutivo que é uma argumentação que se origina dos dados singulares à inferência de uma verdade universal. Ideia que parte da proposição particular para a geral. Não se pode afirmar que a conclusão do argumento é uma verdade.

\section{3) Exemplo III:}

a) Pesquisa de opinião.

b) Maria é mulher e respira.

Rosa é mulher e respira.

Ana é mulher e respira.

Todas as mulheres respiram.

Chauí (2000) salienta que, como todo raciocínio, a Lógica funciona através de três princípios lógicos formais fundamentais, condições de verdade:

I) Princípio da Identidade: Veracidade das ideias, um ser é sempre idêntico a si mesmo, aquilo é o que é: $\mathrm{A}$ é $\mathrm{A}$

Exemplo: Livro é livro

Mesa é mesa

Óvulo \# ser humano

II) Princípio da Não Contradição: Nenhum pensamento ao mesmo tempo, pode ser verdadeiro ou falso. É impossível que um ser seja e não seja idêntico a si mesmo e ao mesmo tempo e na mesma relação. É impossível A é A.

Exemplo: Pedro é professor - Pedro não é professor. 
III) Princípio do $3^{\circ}$ Excluído: É a não contradição das ideias. Dada duas proposições com o mesmo objetivo e o mesmo predicado, uma afirmativa e outra negativa, uma delas é necessariamente falsa $\mathrm{A}$ é $\mathrm{x}$ ou não, não havendo terceira possibilidade.

Exemplo: A vida é longa ou a vida é curta.

Cabe, também, apresentar conceitos básicos para funcionalidade da lógica, tais como:

I) Premissa: Enunciado com razões para sustentar uma afirmação, possibilitando argumentos para conclusão (Tese).

II) Inferência: Operação intelectual que afirma através das proposições, por meio de sua ligação (Teóricos).

III) Argumento: Grupo de premissas - é um conjunto de afirmações de frases, onde se conclui algo que se chega a um raciocínio argumentativo (Análise).

Lefebvre considera necessária a compreensão da Lógica Formal, permite compreender a lei fundamental, o pensamento que conhece, opera sobre um conteúdo, mas deve assimilar esse conteúdo progressivamente, sem deixá-lo no plano global e confuso, mas admiti-lo apenas quando analisado e, quando determinado pelo trabalho, ao mesmo tempo duplo e unitário, do entendimento e da razão (LEFEBVRE, 197I, p. I69).

Portanto, é discutível se as regras da Lógica Formal ensinam alguém a pensar, e levam a uma verdade absoluta, porém é indiscutível que ajudam a corrigir argumentos falsos e tendenciosos (PATRUS, 2002, I45). Assim, faz-se pertinente compreendermos em mesma medida os processos que conduzem a Lógica Dialética.

\section{A LÓGICA DIALÉTICA}

A trajetória histórica de construção da Lógica é em si, um movimento dialético. Concebida, reconstruída e aberta a ser questionada, como já foi tratado anteriormente, pode-se dizer que existem "lógicas" já que está se aplica a diferentes campos tendo como objeto as formas do pensamento, mais especificamente a mais complexa, o raciocínio.

Para se falar em lógica dialética é necessário resgatar a trajetória da construção desse entendimento. Nela, é possível identificar a presença de elementos da contradição dialética muito antes de suas leis terem sido elaboradas pelos gregos enquanto lógica do provável. 
Pode-se dizer assim, que seus primeiros entendimentos estão presentes em registros bem mais remotos da humanidade, não da forma como a entendemos hoje, mas enquanto premissas.

É o caso dos escritos da doutrina de Lao Tsé ${ }^{6}$ em que a contradição dialética representa a própria ação, o mestre afirmava que os movimentos do dao (TAO) ${ }^{7}$ realizamse através dos opostos, onde o "dao" se manifesta no que há e este em polaridades que se apresentam como processos e estão manifestos em formas múltiplas e estas formas segundo ele tem sua estabilidade a partir da interação entre as polaridades. (LAO-TSÉ, 1997). Desse modo, já estavam presentes em sua doutrina elementos que fariam parte futuramente do entendimento sistemático do que viria a ser a dialética.

O termo dialética que tem origem grega dialektiké e deriva de diálogo não foi empregado segundo Abbagnano (2012) de uma única forma no decorrer da história, podendo-se distinguir segundo ele, até quatro significados de acordo com as doutrinas que influenciaram a história do termo, são elas: a platônica, a aristotélica, a estoica e a hegeliana. Desse modo, tem-se a dialética como "[...] método de divisão, como lógica do provável, como lógica e como síntese dos opostos" (ABBAGNANO, 2012, p. 215).

Premissas filosóficas que viriam inspirar o pensamento dialético, bem como sua oposição, marcaram filósofos muito antes das doutrinas aqui referidas no período que se caracteriza como o nascimento da filosofia grega marcada pela busca de explicações existenciais dos seres, o devir. Duas foram as grandes tendências que se contrapunham em pensamento nesse período e foram defendidas pelos pré-socrático Heráclito de Éfeso e Parmênides de Eléia. Assunto tratado no item anterior desse artigo.

Segue-se a isso na história da filosofia grega a busca de afirmação das duas doutrinas que entendem a racionalidade da realidade sendo contraditória em Heráclito e de identidade imutável em Parmênides. O percurso aqui escolhido segue os filósofos que compreendem a realidade a partir da contradição e da mudança permanente na tentativa de

\footnotetext{
${ }^{6}$ Lao-Tsé, fundador da doutrina taoíta na China; O principal texto do taoísmo é o Tao Te King (Livro do Caminho e da Virtude), atribuído a Lao-Tsé (ABBAGNANO, 2orz).

7 "Tao" significa "caminho", e faz parte de várias filosofias e religiões chinesas, mas é base filosófica, principalmente do Taoismo, conhecimento que se relaciona à fonte, à dinâmica e à força que há em tudo que existe". Em: TAOISMO. 2018. Disponível em: https://pt.wikipedia.org/wiki/Taoismo. Acesso em: ro nov. 2018.
} 
se elucidar a lógica dialética nessa trajetória até a compreensão que se tem hoje (FOULQUIÉ, 1966).

Nesse percurso, o Pré-Socrático Zenão de Eléia, discípulo de Parmênides destaca-se com seu método de elaboração de paradoxos sendo considerado por Aristóteles o criador da dialética. Zenão não combatia as teses que refutava e sim buscava mostrar a falsidade e os absurdos dos estudos inválidos, ou seja, ele realizava a refutação da refutação. Desse modo, a dialética em Zenão se tornou o instrumento da razão por excelência, um método do pensamento a partir de confrontação de teses, procurando com seus paradoxos combater argumentos falaciosos e que não resistiam às refutações.

O método de refutação de Zenão, a forma de argumentar a partir de seus paradoxos ficou conhecida por ter estrutura de redução ao absurdo. Zenão partia da própria posição de seus adversários conduzindo-os ao absurdo até serem convencidos do contrário, ou seja, o raciocínio aqui parte não de premissas verdadeiras e sim as admitidas pelo seu opositor, como destaca Abelardo (1969, p. 139) "[... ] ninguém pode ser refutado senão a partir do que concede, nem convencido senão pelo que admite". Essa técnica dialética mesclada com a retórica se faz presente na área do direito, bem como no campo da matemática.

Posteriormente, pode-se considerar que nesse percurso o método dialético ganha maturidade com os sofistas, considerados filósofos itinerantes e livres que ensinavam a aqueles que queriam destaque público a arte em discursos que combatiam as oposições sustentadas pelos adversários. A dialética era utilizada pelos sofistas como instrumento do discurso, sem preocupação científica ou filosófica, sem compromisso com a verdade, servindo apenas aquilo que era útil e oportuno.

Sócrates se opunha aos sofistas, para ele a busca da verdade e da virtude a partir da estruturação do pensamento só é alcançada através do conhecimento, e para se chegar a este, é necessário o método dialético. Em Sócrates o diálogo como própria essência do filosofar torna a dialética instrumento da ágora, entendida "[...] como um debate, uma discussão, um diálogo entre opiniões contrárias e contraditórias para que o pensamento e a linguagem passem da contradição entre as aparências a identidade de uma essência. (CHAUI, 2000, p. I8I).

Descrito em seus diálogos, o método socrático realizava um embate que levava as pessoas a refletirem sobre suas próprias colocações e argumentos. Sócrates partia de 
indagações, descrito em diálogos como em Fédon era entendido como “[...] um método mediante o qual uma hipótese é formulada e testada em seguida em busca de coerência" (HAMLYN, 1990, p. 33). Sócrates dizia que para se alcançar conhecimento era necessário espírito crítico e o reconhecimento da própria ignorância. $O$ método dividia-se em três fases: ironia; refutação e a maiêutica, realizando-se com isso o parto de ideias através de perguntas e respostas.

Posteriormente, Platão transforma essa prática em método de formação e teste de hipóteses. Diante do dilema posto por Heráclito e Parmênides, Platão considerou que o primeiro tinha razão, pois para ele a matéria está sujeita a mudanças contínuas e a oposições internas, o mundo sensível é o devir permanente, mas este é um mundo de aparências, sombra do mundo verdadeiro e real das essências imutáveis que o filósofo chama de mundo inteligível, nesse caso, para Platão, Parmênides tinha razão (CHAUI, 2000, p. I8I). Essa concepção em Platão é conhecida por Teoria das Ideias ou Teoria das Formas. Platão utiliza-se da "alegoria da caverna" para explicar como é possível conhecer as essências e abandonar as aparências e isso só seria possível através de um método do pensamento e da linguagem chamado dialética. $O$ método dialético segundo exposto por Platão seria o meio pelo qual as hipóteses seriam desfeitas, permitindo um autêntico caminho para se chegar a resultados seguros (PLATAO, 1949).

Platão considerava a dialética essencial para o entendimento da realidade, aprisionados na caverna a mercê das interpretações da visão apenas de sombras vagas, se libertar era necessário para descobrir o mundo real e isso era possível através da luz, saindo-se da caverna. Para ele, é necessário a separação dos opostos, para que conhecendo sua contradição se avance na identificação do que é verdadeiro, que se chegue a um termo indivisível, essa ideia seria da verdade, a essência. Nesse sentido, a dialética aparece em Platão como método de divisão, como uma técnica de investigação conjunta, com a colaboração de duas ou mais pessoas segundo o que Sócrates havia já formulado, um diálogo de perguntas e respostas (ABBAGNANO, 2012, p. 315).

Platão afirmava que dessa investigação conjunta, a dialética seria o ponto mais alto passando por dois momentos: o primeiro seria remeter as coisas dispersas a uma ideia única, definindo-a a ponto que possa ser comunicada a todos e a segunda seria poder dividir novamente a ideia seguindo suas interações naturais. A dialética em Platão auxilia 
o alcance do conhecimento autêntico, a episteme como conhecimento da realidade das coisas.

Aristóteles diferente de Platão concebe a dialética como lógica do provável não separando realidade e aparência. Não entende a mudança como aparência ilusória, acredita que há no mesmo mundo seres de essência mutáveis e outros imutáveis. Para o filósofo a dialética é um procedimento racional não demonstrativo. Não a considerava um procedimento seguro, já que se baseava em opiniões contrárias prevalecendo ao final uma delas e isso não garantia segundo o filósofo o alcance da essência. Dialético para ele é 'o silogismo que, em vez de partir de premissas verdadeiras, parte de premissas prováveis, geralmente admitidas'.

Aristóteles contrapõe a dialética a ciência da demonstração, a analítica que se ocupa de raciocínio demonstrativo. A dialética na sua visão servia mais a retórica, a assuntos onde a persuasão prevalecesse. Sua analítica como um instrumento que antecede o pensamento na construção do conhecimento é base para o que se considera conhecimento científico, pois enquanto para Platão a dialética era um modo de conhecer, para Aristóteles a analítica era um instrumento para conhecer a partir de princípios, regras e leis que levam a um conhecimento universal (CHAUI, 2000, p. I82).

A dialética após Aristóteles foi abordada em diferentes perspectivas por inúmeros filósofos em tempos e realidade diferentes. Mas a compreensão dos estoicos, unindo a lógica, retórica e gramática foi a mais difundida na Antiguidade e por toda a Idade Média (ABBAGNANO, 2012, p. 318). Era assim utilizada como o conceito de lógica em geral.

Muito do que foi abordado pelos estoicos sobre a dialética estaria presente posteriormente no que Hegel formulou enquanto síntese dos opostos. Considerado criador da dialética moderna, para ele a dialética enquanto sistema de compreensão da realidade tem na contradição o elemento que a rege. No entanto, para ele, está não poderia se restringir apenas a afirmação/negação, mas também em consenso representado pela síntese.

O princípio dialético sistematizado por Hegel foi anteriormente apresentado por Abbagnano (2012) e por Fichte (1984), mas enquanto para Fichte a síntese se revela como representação, para Hegel a dialética é a própria natureza do pensamento. Em sua obra "A Ciência da Lógica" Hegel expõe sua teoria dialética, onde introduz a inovação para além do que Platão havia apresentado e destaca que o conflito entre os opostos - tese e antítese - 
não é ideal, mas real, uni com isso, idealismo e história e tem assim, no conceito de totalidade o elemento necessário à compreensão da história da razão e da realidade.

Em Hegel, a própria história é um movimento dialético que se dá a partir da tese sua antítese e síntese. Da mesma forma ele explica o funcionamento da razão onde a tese aparece como a afirmação do próprio ser, a antítese como a negação da tese e a síntese como a negação da negação. Enquanto negação da negação se retorna a uma nova tese em um movimento dialético onde os elementos não são eliminados, mas estão presentes, ou seja, o que é negado não é eliminado ou destruído, mas é remetido a uma nova síntese pela própria contradição que é inerente a esse processo.

Diante disso, pensar a Lógica Dialética para análise da realidade concreta envolvendo os sujeitos é ter clareza como aponta Abbagnano (2012, p. 320) que "[...] o objeto e o resultado da metodologia dialética é, pois, uma 'totalidade concreta' na qual os fenômenos sociais surgem numa relação constitutiva e dinâmica com o conjunto da sociedade e da história”. Nesse sentido, a Lógica Dialética, permite a apreensão de uma realidade por meio da noção de totalidade, contradição e mudança.

\section{CONSIDERAÇÕES FINAIS}

O presente trabalho evidenciou a importância do raciocínio lógico nas diversas atividades da vida do ser humano, observando-se que na maioria das situações postas em pesquisa, sabe-se perfeitamente o que é raciocínio lógico e, consegue-se expressar com palavras. No entanto, percebeu-se uma dificuldade, constatada e superada no processo, de transpor as ideias da teoria para a prática.

No geral, cabe inferir que no universo pesquisado é possível definir bem o que é, onde e quando aplicar o raciocínio lógico. Porém, também, consideram-se o fato de imprevistos acontecerem e em determinadas situações, poucos conseguem manter um equilíbrio e raciocinar de forma lógica. Nestes termos, o que mais ocorre é a impulsividade, a decisão rápida e muitas vezes impensada.

Resgatou-se, na proposta deste artigo, a história da Lógica, no concernente à importante contribuição que a civilização grega ofereceu, por meio dos primeiros filósofos, para o aparecimento e consolidação da Lógica nos primórdios da civilização, que ao longo 
do tempo recebeu outras e preciosas contribuições, em especial na Idade Média através de membros da Escolástica.

A Lógica, aqui estudada, foi agrupada de forma a mostrar a sua contextualização, a importância para a vida do ser humano e os encaminhamentos da Lógica Dialética nesse processo. Dessa forma, cabe afirmar que a Lógica se aplica a todos os objetos do pensamento, que compreendem a apreensão, o juízo e o raciocínio, isto é, da apreensão e da ideia, do juízo e da proposição e, do raciocínio e da argumentação.

\section{REFERÊNCIAS}

ABBAGNANO, N. Dicionário de filosofia. São Paulo: Martins Fontes, 2012.

ABELARDO, P. Prologue du Sic et Non. In: JOLNET, J. (Org.). Abelard ou la philosophie dans le langage. Paris: Seghers, 1969.

AVILlANO, I. C. Algoritmos e Pascal. São Paulo: Ciência Moderna, 2006.

CHAUÍ, M. Convite à Filosofia. São Paulo: Ed. Ática, 2000.

COPI, I. M. Introdução a Lógica. Trad. Álvaro Cabral. 2. ed. São Paulo: Mestre Jou, 1978.

FICHTE, J. G. A doutrina da ciência de 1794. Trad. Rubens R. T. F. In:

Pensadores. São Paulo: Abril Cultural, 1984.

FORBEllONE, A. L. V.; EBERSPÃCHER, H. F. Lógica de Programação: a construção de algoritmo e estrutura. 3. ed. São Paulo: Pearson Prentice Hall, 2005.

FOULQUIÉ, Paul. A dialéctica. Trad. Luís A. C. Lisboa: Publicações Europa- América, 1966.

HAMLYN, D. W. Uma História da Filosofia ocidental. Trad. Ruy J. Rio de Janeiro: Jorge Zahar Editor, 1990.

LAO-TSÉ. Escritos do curso e sua virtude (Tao Te Ching). Trad. Mário Bruno Sproviero. São Paulo: Editora Manclruvá, I997.

LEFEBVRE, H. Lógica formal e lógica dialética. Trad. Carlos Nelson Coutinho. 5. ed. Rio de Janeiro: Editora Civilização Brasileira S.A, ı99ı.

LIARD, L. Lógica. São Paulo: Companhia Editora Nacional, ig65.

MARITAIN, Jacques. Elementos de Filosofia 2: a ordem dos conceitos, lógica menor. Rio de Janeiro: Agir, I98o. 
PATRUS, Roberto. A lógica formal: princípios elementares. Revista Economia \& gestão, Belo Horizonte, v.2, n.3, p. 135-I45, jan./jun. 2002.

PLATÃO. A República. Trad. Maria H. da R. P. 9. ed. Lisboa: Fundação Calouste Gulbenkian, 1949 . 